\title{
Histoplasmosis: An Important Mycosis of Public Health Significance
}

\section{Pal M*}

Director of Veterinary Public Health and Microbiology, India

*Corresponding author: Mahendra Pal, Founder Director of Narayan Consultancy on Veterinary Public Health and Microbiology, Gujarat, India, Email: palmahendra2@gmail.com

\section{Mini review \\ Volume 4 Issue 2}

Received Date: August 10, 2021

Published Date: August 30, 2021

DOI: $10.23880 /$ oajmms-16000144

\section{Abstract}

Histoplasmosis, a highly infectious fungal disease of public health concern, is caused by Histoplasma capsulatum var. capsulatum, a dimorphic fungus that occurs in mycelial and yeast form. The respiratory tract is recognized as the primary site of $H$. capsulatum var.capsulatum and the infection is acquired by inhalation of fungal spores from the saprobic environment. Disease can occur in sporadic as well as in epidemic form causing morbidity and mortality in susceptible individuals. Sporadic cases of histoplasmosis are reported from over 60 countries of the world including India. In USA, 25,000 cases of histoplasmosis are diagnosed every year. Certain groups of people who are associated with the soil related activities are at greater risk for developing the severe forms of disease. The fungus has the potential to infect every organ of the body including the skin, lung, brain, eye, adrenal gland, heart, liver, spleen, nose, gastrointestinal tract etc. The infection remains asymptomatic in over $90 \%$ of cases. The clinical presentation is varied and the affected person shows fever, headache, dry cough, dyspnea, chest pain, profuse sweating, lymphadenopathy, lesions in the mouth and skin etc. histoplasmosis in immune compromised patients, especially suffering from AIDS has poor prognosis. Mycological, immunological, and molecular techniques are employed to confirm an unequivocal diagnosis of disease. However, the isolation of $H$. capsulatum var. capsulatum from the clinical specimens still considered the gold standard of diagnosis. Antifungal drugs like liposomal amphotericin B and itraconazole are recommended for the management of disease. The disseminated histoplasmosis can be fatal if left untreated. It is imperative that immune compromised persons must avoid visiting the heavily contaminated sites that are inhabited by bats excreta and avian droppings.

Keywords: AIDS; Bat droppings; Histoplasma capsulatum var.capsulatum; Public Health; Respiratory Tract

\section{Introduction}

Mycotic diseases are important from public health and economic point of view, and are reported from developing as well as developed countries of the world. It is believed that about 800 million people in world have suffered from one or other types of fungal diseases thus indicating the importance of mycoses in human health [1]. Mycoses caused by many species of fungi, are reported in both sexes, all age groups, in all seasons, urban and rural areas, in all climatic zones and in immune competent and immune compromised subjects throughout the world [2]. Maximum cases of invasive fungal infections have been encountered in immune compromised patients, especially suffering from HIV/AIDS. The high mortality encountered due to invasive mycotic infections is of immense public health concern [2]. In the absence of 


\section{Open Access Journal of Mycology \& Mycological Sciences}

therapy, disseminated mycoses often carry a grave prognosis. Therefore, it is very essential to institute antifungal treatment as early as possible to save the life of the patient [1].

histoplasmosis also known as caveran disease, Darling's disease, reticuloendothelial ctomycosis, Tingo Maria fever, is an important mycotic disease of reticuloendothelial system, which has been recorded in humans and animals [1]. The history of hisptoplasmosis goes back to year 1905 when Samul Taylor Darling described the first case of disease in a patient during autopsy from Panama, USA $[1,3]$. The first report of ante-mortem diagnosis of histoplasmosis in a child from the USA was made by Katherine Dodd [4]. Dimorphism in Histoplasma capsulatum was discovered by de Monbreun in 1934 [5]. The first report of naturally occurring histoplasmosis in canine was recorded from USA in 1939 by de Monbreun [6]. The saprophytic existence of H.capsulatum was reported by Emmons in 1949 by isolating H.capsulatum from the soil [7]. The association of bat with histoplasmosis was elucidated in 1958 by Emmons [8]. In India, Panja and Sen are credited to record the first case of histoplasmosis from Kolkatta in 1954 [3,4]. Co-infection due to tuberculosis and histoplasmosis are reported in AIDS patients [9]. Adenis and co-investigators [10] described histoplasmosis in HIV infected patients. Very recently, Messina and co-investigators [11] reported COVID-19 in a patient with disseminated histoplasmosis and HIV. A massive outbreak histoplasmosis among the school students was investigated in Indiana, USA during 2001 [12]. It is mentioned that the skin lesions can occur in 10 to $35 \%$ of the immune compromised patients with disseminated histoplasmosis [13]. Though the disease is endemic in the American continent, sporadic cases are reported from many nations including India $[14,3,4,15]$. It is estimated that 25,000 cases of histoplasmosis are reported annually in the USA [16]. Histoplasmosis is considered as an occupational disease of gardeners, cavers, miners, spelunkers, construction workers, geologists, tourists, and military personnel who are exposed to the soil due to outdoor activities $[1,3]$. The present paper describes the public health importance of histoplasmosis that is caused by H.capsulatum var.capsulatum.

\section{Etiology}

Histoplasmosis is caused by three varieties of Histoplasma capsulatum namely H.capsulatum var.capsulatum (American Histoplasmosis, Classic Histoplasmosis, has wider distribution, reported in humans and several species of animals) [1], H.capsulatum var.duboissii (African histoplasmosis, occurs in baboon and humans in Africa) [1], and H.capsulatum var.farciminosum (cause of epizootic lymphangitis in animals, mainly affecting equines in Ethiopia) [17]. Histoplasma capsulatum is a dimporhic fungus that grows in mould (mycelial) form in nature and on Sabouraud dextrose agar medium at $25^{\circ} \mathrm{C}$; and also in yeast phase in host tissues and on brain heart infusion agar (BHI) medium at $37^{\circ} \mathrm{C}$. It is mentioned that the mould stage produces microaleurio spores and macroaleurio spores [18]. The fungus can survive from $18^{\circ} \mathrm{C}$ to $37^{\circ} \mathrm{C}$ of environmental temperature [1]. H.capsulatum var. capsulatum, the etiological agent of human and animal Histoplasmosis, has been isolated from the soil, and bat guano and also from droppings of other avian like starling, parrot, chicken, and oil birds [1].

\section{Host}

The natural infection due to H.capsulatum var.capsulatum is described in humans and also in a wide variety of animals, such as bat, cat, cattle, dog, ferret, fox, horse, monkey, marmot, mouse, opossum, pig, raccoon, rat, shrew, skunk, sheep, and woodchuck [1,18]. Among animals, maximum cases are encountered in dogs from the US [3]. Though H.capsulatum var.capsulatum has been frequently recovered from the avian droppings, the birds are not affected with this dimorphic fungus [1].

\section{Transmission}

The inhalation of infectious fungal conidia from the saprobic environment is considered as the primary mode of infection of histoplasmosis.

Rarely, laboratory acquired infections may occur when the spores of H.capsulatum var. capsulatum can enter through inoculation in the skin and mucous membranes. Noscocomial infection is also observed in hospital settings [18]. There is no evidence that disease is communicable from animal to human and vice-versa [1].

\section{Clinical Symptoms}

Histoplasma capsulatum var. capsulatum is a primary pathogen that can produce disease in immune competent and immune compromised patients. The majority of people who are exposed to the fungus do not develop any symptoms. However, in some persons, the symptoms occur within 3 to 17 days following the inhalation of the fungal conidia from the saprobic environment where the fungus grows [19].

Several clinical types of histoplasmosis, such as acute pulomanry, chronic pulomary, cutaneous, mucocutaneous and disseminated are described [4]. The affected person shows the symptoms of fever, headache, cough, sore throat, chest pain, hemoptysis, dyspnea, chills, sweats, body aches, splenomegaly, lymphadenopathy, anemia, hepatomegaly, endocarditis, meningitis, fatigue, weight loss, ulcers on the mouth, pharynx, larynx, and skin lesions $[1,18]$. Fever is a frequently observed symptom of histoplasmosis [19]. The 


\section{Open Access Journal of Mycology \& Mycological Sciences}

clinical manifestation of disease in cats and dogs is like to histoplasmosis in humans [1].

\section{Diagnosis}

Due to nonspecific clinical manifestation of Histoplasmsois, the laboratory help is imperative to establish a correct diagnosis of disease to institute the antifungal therapy to mitigate the suffering of the patient. The cytological examination of stained smear of bronchoalveolar lavage (BAL) with Gomori metanamine silver (GMS) and periodic acid Schiff (PAS) method is very useful in diagnosing the disease $[1,18]$. The isolation of the pathogen can be attempted from clinical specimens, such as sputum, blood, BAL, tissue biopsy etc. on several nutrient media like bold agar, blood glucose cysteine agar, brain heart infusion and Sabouraud medium $[1,18]$. The detailed microscopic morphology of fungal culture can be studied in a newly developed stain designated as Nararan [20]. Narayan stain contains $6.0 \mathrm{ml}$ of dimethyl sulphoxcide, $4.0 \mathrm{ml}$ of glycerin, and $0.5 \mathrm{ml}$ solution of $3 \%$ solution of methylene blue.

Immunological techniques such as AGID and CFT can demonstrate the presence Histoplasma antibodies in the sera of affected patients $[1,4,18]$. Molecular tools have been used to detect H.capsulatum var. capsulatum in human clinical samples [21-23]. Histoplasma skin test, based on the delayed type hypersensitivity, is commonly employed for epidemiological surveys to identify the endemic areas of histoplasmosis [1].

It is advised that histoplasmosis should be differentiated from other diseases such as tuberculosis, coxiellosis, legionellosis, blastomycosis, chlamydiosis, toxoplasmsois, parracoccidioidomycosis, syphilis, leprosy, sarcoidosis, leishmaniasis and Mycoplasma pneumoniae infection $[1,4,15]$.

As disseminated histoplasmosis is an important cause of mortality in HIV-infected patients, it is, therefore, very essential to make a quick and efficient diagnosis of disease to immediately start the treatment for saving the life of the patient.

\section{Treatment}

The majority of acute histoplasmosis cases in persons with healthy immune system are likely being resolved spontaneously without any treatment [24]. However, treatment is imperative when the infection is disseminated or the patient is highly immune compromised. Amphotericin $B$ remains the main stay of therapy for the management of histoplasmosis [4]. Due to its high toxicity, liposomal amphotericin B can be tried. Itraconazole is another drug that has shown promising results in the treatment of disease [1]. As these antifungal antibiotics are very expensive and not easily available in many countries of the world [25], it is highly imperative to develop safe, effective and cheap drugs that can be used even by poor resource nations.

\section{Prevention and Control}

Presently, no vaccine is available to immunize the susceptible people. Therefore, certain measures, such as use of protective clothing when exploring caves, cleaning chicken coops, and visiting old monuments, historical buildings, abandoned mines, tunnels, decontamination of bat habitat, chicken coop, and other infected sites with spraying 3 to $5 \%$ solution of formalin may be helpful to minimize the incidence of disease $[1,18]$. Furthermore, it is advised that immune compromised persons should not visit any highly contaminated site or engaged in the soil related activities. The persons who are traveling to the endemic countries should take precautions when visiting the old monuments or caves.

\section{Conclusion}

Histoplasmosis, an important systemic mycosis of humans and animals, is caused by Histoplasma capsulatum var. capsulatum that lives in the environment, mainly in the soil enriched with fecal matter of bats and birds. The infection is mostly asymptomatic in immune competent individuals. It can cause life-threatening infection in the immune compromised patients. The source of infection is exogenous, and there are evidences to believe that both humans and animals may acquire the infection from the environment where the fungus grows as saprobe. The disseminated histoplasmosis can affect any part of the body, such as the lung, brain, heart, liver, spleen, mouth, skin, and adrenal glands. There is a need to develop sensitive diagnostic tests, safe and easily available low cost chemotherapeutic agents for the better management of disease. Further work on the molecular epidemiology, risk factors, pathogenesis and vaccinology should be conducted.

\section{Acknowledgements}

The author is very grateful to Prof. Dr. R.K. Narayan for his critical comments during the preparation of the manuscript. Thanks are also due to Anubha Priyabandhu for computer help. This paper is dedicated to all the Indian Kings who scarified their lives to protect the nation from foreign invaders.

\section{References}

1. Pal M (2007) Veterinary and Medical Mycology. $1^{\text {st }}$ 


\section{Open Access Journal of Mycology \& Mycological Sciences}

(Edn.), Indian Council of Agricultural Research, New Delhi, India.

2. Pal M (2017) Morbidity and mortality due to fungal infections. Journal of Applied Microbiology and Biochemistry 1: 1-3.

3. Pal M [2017] Ecology of Histoplasma capsulatum var. capsulatum. Vaccines and Vaccination Open Access 2: $1-2$.

4. Chander J (2009) Medical Mycology. $3^{\text {rd }}$ (Edn.), Mehta Publishers, New Delhi, India.

5. De Monbreum WA (1934) The cultivation and cultural characteristic of Darling's Histoplasma capsulatum. Am J Trop Med 14(2): 93-125.

6. De Monbreum WA (1939) The dog as a natural host for Histoplasma capsulatum. Am J Trop Med 19(6): 565-587.

7. Emmons CW (1949) Isolation of Histoplasma capsulatum from soil. Pub Health Rep 64(28): 892-896.

8. Emmons CW (1958) Association of bats with histoplasmosis. Pub Health Rep 73(7): 590-595.

9. Agudelo CA, Restrepo CA, Molina DA, Tobón AM, Kauffman CA, et al. (2014) Tuberculosis and histoplasmosis coinfection in AIDS patients. Am J Trop Med Hyg 87(6): 1094-1098.

10. Adenis A, Nacher M, Hanf M, Basurko C, Dufour J, et al. [2014] Tuberculosis and histoplasmosis among human immunodeficiency virus- infected patients: A comparative study. Am J Trop Med Hyg 90(2): 216-223.

11. Adenis AA, Aznar C, Couppié P (2014) histoplasmosis in HIV-infected patients: a review of new developments and remaining gaps. Curr Trop Med Rep 1(2): 119-128.

12. Messina FA, Marin E, Caceres DH, Romero M, Depardo R, et al. (2020) Coronavirus disease (COVID-19) in a patient with disseminated histoplasmosis and HIV-A case report from Argentina and literature review J Fungi 6(4): 275.

13. Chamany S, Mirza SA, Fleming JW (2004) A large outbreak of histoplasmosis among high school students in Indiana, 2001. Pediatr Infect Dis J 23(10): 904-914

14. Chang P, Rodas C (2012) Skin lesions in histoplasmosis. Clini Dermatol 30(6): 592-298.

15. McLeod DS, Mortimer RH, Perry-Keene DA, Allworth A, Woods ML, et al. (2011) histoplasmosis in Australia: report of 16 cases and literature review. Medicine 90(1): 61-68.
16. Patra S, Nimitha R, Kaul S, Valakkada J, Verma KK, et al. (2018) Primary cutaneous histoplasmosis in an immune competent patient presenting with severe pruritis. Indian J Dermatol Venereol Leprol 84(4): 465-468.

17. Brown GD, Denning DW, Gow NAR, Levitz SM, Netea MG, et al. (2012) Hidden killers: Human fungal infections. Science Translation Medicine 4(165): 1-6.

18. Pal M (2019) Occurrence of cutaneous epizootic lymphangitis in working donkeys in Debre Zeit, Ethiopia. EC Microbiol 15: 382-384.

19. Pal M (2007) Zoonoses. $2^{\text {nd }}($ Edn.), Satyam Publishers, Jaipur, India.

20. Cano MV, Hajjeh RA (2001) The Epidemiology of histoplasmosis: A review. Semin Respir Infect 16(2): 109-118.

21. Pal M (2004) Efficacy of Narayan stain for the morphological studies of moulds, yeasts and algae. Rev Iberoam de Micol 21(4): 219.

22. Bracca A, Tosello ME, Girardini JE, Amigot SL, Gomez C, et al. (2003) Molecular detection of Histoplasma capsulatum var. capsulatum in human clinical samples. J Clin Microbiol 41(4): 1753-1755.

23. Babady NE, Buckwalter SP, Hall L, Le Febre KM, Binnicker MJ, et al. (2011) Detection of Blastomyces dermatitidis and Histoplasma capsulatum from culture isolates and clinical specimens by use of Real-Time PCR. J Clin Microbiol 49(9): 3204-3208.

24. Scheel CM, Zhou YT, Theodoro RC, Abrams B, Balajee SA, et al. (2014) Development of a loop-mediated isothermal amplification method for detection of Histoplasma capsulatum DNA in clinical samples. J Clin Microbiol 52(2): 483-488.

25. Kauffman CA (2007) Histoplasmosis: a clinical and laboratory update. Clin Microbiol Rev 20(1): 115-132.

26. Johnson PC, Wheat LJ, Cloud GA, Goldman M, Lancaster D, etal. (2002) Safety and efficacy of liposomal amphotericin B compared with conventional amphotericin B for induction therapy of histoplasmosis in patients with AIDS. Ann Intern Med 137(2): 105-109. 